\title{
Vices and Virtues in Capacity Development by International NGOs
}

\author{
Rick James
}

\begin{abstract}
We know what works in capacity development: a succession of studies from official agencies, academics and NGO practitioners have all highlighted similar principles of good practice. But the evidence also suggests that there is a distressing dissonance between what international development agencies know about capacity development and what they implement. This article explores the reasons for this failure. It highlights constraints that arise from the changing aid context and from a lack of resources and skills. Ultimately, however, it concludes that capacity development is driven more by self-interest than by knowledge of what works. Until agencies' pride, greed and self-interest can be restrained, much capacity development will continue to be disappointing and ineffective. But if agencies combine existing professional knowledge with virtues of humility, patience and a genuine commitment to others, then capacity development becomes something that can bring transformation.
\end{abstract}

\section{Introduction}

We know what works in capacity development: a succession of studies from official agencies, academics and NGO practitioners have all highlighted similar principles of good practice. The issue is not about knowledge. The problem is that development agencies are not putting into practice what they know. Self-interest takes precedence. To narrow the gap between what we know and what we do, requires us to acknowledge and manage our self-interests; to put into practice virtues of humility, honesty, justice, determination and hope.

This article is developed from an INTRAC publication Capacity Building for NGOs: Making it Work (James and Hailey 2007). It starts by highlighting some key principles of good practice that have emerged from 20 years of INTRAC experience in capacity development with NGOs. These findings resonate with other studies both with NGOs and from the public sector. The article goes on to analyse the current practice of international development agencies in the light of these principles. It identifies a serious gap between what agencies know about capacity development and what they practice. The article then explores the reasons for this failure to implement good practice. It highlights constraints that arise from the changing aid context and from a lack of resources and skills. Ultimately, however, it concludes that capacity development is driven more by self-interest than by knowledge of what works. Until agencies' pride, greed and self-interest can be restrained, much capacity development will continue to be disappointing and ineffective. But if agencies are able to combine sound professional knowledge with the virtues of humility, patience and a genuine commitment to others, then capacity development becomes a real possibility.

\section{We know what to do}

Capacity development, or capacity building as some prefer, has suffered from the lack of a tight, internationally-accepted definition. It is a nebulous concept - broad, contested, ambiguous, and imprecise. This causes confusion within and between agencies. The elasticity allows different stakeholders to ascribe their own meaning to capacity development and interpret it, unchallenged, from their own perspective.

Yet there has been progress in defining capacity development and in distilling good practice. A number of recent studies from a diversity of 
sources and sectors show there are important emerging areas of conceptual congruence.

Official agency studies (Baser and Morgan 2008; UNDP 2006; DAC 2006); academic writers (Morgan 2006; Fowler 2006; Eyben 2006); international NGOs research (Lipson and Warren 2006) and action learning from capacity development practitioners (James and Wrigley 2007) all agree that capacity development:

- is a complex, human process based on values, emotions, and beliefs;

- is an internal process (endogenous - 'formed from within') that involves the main actor taking responsibility for the process of change;

- involves shifts in power and identity;

- involves changes in relationship between elements of open-systems;

- is uncertain and unpredictable;

- is powerfully influenced by the culture and the changing context.

In consequence, there is also general agreement on the principles of good practice in capacity development. These resonate with the principles highlighted by James and Hailey (2007) who assert that good capacity development:

- is a human, client-centred approach that:

1. is people-centred and engages with values

2. ensures client responsibility for change

3. addresses issues of power and relationship.

- has a locally appropriate and sustainable delivery process that:

4. involves a variety of techniques

5. explicitly adapts to the particular context and culture

6. uses and develops skilled local capacity building providers.

is well planned and managed which:

7. pursues a carefully planned and 'situational' strategy

8. focuses on implementation of the change process

9. has developmental resourcing

10.systematically assesses and learns from experience.

While the language may vary, the underlying principles are similar. There is an unusual consensus between a wide diversity of stakeholders about what works in capacity development. The issue then is not about knowledge. We know what to do in capacity development. The question is whether we put into practice what we know.

\section{Distressing dissonance - the gap between theory and practice}

The evidence that we have is not encouraging. As we shall see, there is a significant gap between what international agencies know about capacity development and the sorts of programmes they implement. Performance is patchy. Two major recent studies, one of international NGOs (Lipson and Warren 2006) and another of the World Bank (2006), reveal that international agencies are often falling far short of their own standards of good practice. These findings are not true of all agencies everywhere; some are better than others and within agencies, the quality of programmes may vary. But these shortcomings in implementation mirror other evaluations of individual INGO capacity development programmes that INTRAC has undertaken over the years (Sorgenfrei 2004; Beauclerk 2006 and 2007). There is a distressing dissonance between espoused principles and actions.

If we compare what international NGOs know about good practice in capacity development with their actual implementation, what do we find?

\subsection{To what extent are INGOs taking a human, client- centred approach to capacity development?}

The evidence suggests that many capacity development programmes are not client-centred in that they do not ensure that the client is taking responsibility for change. This is often because donors are tempted to impose their own analysis and try and control the content and process of the intervention too tightly. Capacity development practice contradicts what we know, because donors have continued to set the agenda for capacity development.

\section{Client responsibility}

The World Bank asserts the centrality of country ownership to any development processes, but discovered from its evaluation that 'in the area of public financial management... the countries do not fully "own" the change agenda' (2006: xv). Lipson and Warren's (2006) survey shows that International NGOs (INGOs) act in a similar 
way to the World Bank (2006). Capacity development needs are still largely defined by international agencies. The content of capacity development reflects donor priorities, particularly in their changing context of 'resultsbased management' and 'risk assessment'. For example, over half of the major priorities for Southern capacity development clearly are aimed primarily at meeting Northern needs ${ }^{1}$ for:

- project design and implementation;

- monitoring and evaluation systems development and use;

- impact assessment;

- accountability;

- financial transparency, systems and management.

Survey results suggest that while INGOs emphasised CSO consultation and participation in shaping the capacity development work, only 37 per cent of the respondents stated that they let local partners have total management of the capacity development (Lipson and Warren 2006: 10). Most INGOs prefer to retain control of the capacity development process themselves designing the overall approach, making funding decisions and indeed directly delivering services themselves.

\section{Power and relationships}

Passive acquiescence is not the same as active ownership. Power relationships have a profound influence on capacity development. While many INGOs acknowledge this (Beauclerk 2007; Wrigley 2006), the evidence from the evaluations points to the relatively low priority INGOs give to such issues in a capacity development process. The 2006 INGO survey found that the subject of relationships with Northern partners/donors was second to bottom on the list of priorities. While agencies accept the theory that capacity development involves shifts in power and relationship, they are more ambivalent in practice. Only a minority demonstrated any understanding of capacity development as a twoway process of learning and change.

\subsection{To what extent are INGOs supporting a variety of capacity development techniques through a local delivery process?}

It is clear that INGOs support a wide variety of capacity development techniques, but training and technical assistance are still the most frequently used methods. INGOs support for local providers of capacity development appears to be more instrumental than strategic. They tend to contract them as one-off consultants, rather than supporting their staff and organisation development.

\section{Methods}

According to the INGO surveys and evaluations, training and technical assistance are still the main methods of international agencies' support for capacity development. This is despite the increasingly awareness of their limitations. The World Bank (2006) evaluation found that the 'traditional tools - technical assistance and training - have often proven ineffective in helping to building sustained public sector capacity'. While many international NGOs use a variety of different methodologies in their attempt to diversify their approach to capacity development, most (like many official agencies) continue to rely on training and technical assistance as the two most popular methods (Lipson and Warren 2006).

This over-reliance on these structured, even formulaic, approaches to capacity development suggests that many agencies are avoiding facing up to some of the messy and complex human dimensions of capacity development. By relying on rigid planning frameworks they may have oversimplified capacity development to a purely logical, mechanical process. The timeframes used are based on artificial project cycle deadlines, not what pace of change is possible. Much capacity development avoids (or merely pays lip-service to) sensitive or contentious areas such as cultural values and beliefs, including spirituality and faith.

\section{Local providers}

Almost 25 years ago the need for 'the NGO community to develop its own OD and management services based in the South to provide local consultants, trainers, researchers and evaluators' was identified (Partnership Africa Canada 1986). Nearly half the respondents in a 1994 survey of INGO support to capacity development, asserted that they provided support to Southern NGO training centres. Yet in the 15 years since then, we have seen no real increase in INGO support to local capacity development providers. If anything, there seems to have been a shift from provision 
Support to capacity development has been ad hoc, characterised by a succession of interesting one-off experiments, but no guiding or coherent strategy. As staff have joined or left TINGO, the emphases in capacity development have shifted. Sometimes the capacity development strategy appears to have shifted as a response to new funding or partner fraud with consequent risk management concerns. There is much interesting information on TINGO's approach to capacity development in both published and internal documents, but these appear more individually-owned than organisationally-decided.

TINGO's approach to capacity development has been extensive, but scattered and inconsistent. It has too many focus themes that change regularly. This leaves partners overwhelmed by different priorities. TINGO's capacity development pushes for too fast a pace of change and is too short-term oriented.

Although capacity development is prioritised in the strategic plan, there appears to be more ambivalence in reality. The staff involved in capacity development have not had much power in the organisation to integrate it with the rest of TINGO's practice. The capacity development staff operate as an internal advisory service to the regional programmes, not an implementing department on its own.

Although capacity development is a strategic objective, it only merits one of 19 corporate indicators to measure TINGO performance (and there are grave concerns about the usefulness of that single indicator). Staff perceive that TINGO is largely driven by its grant management ('bank') function, not its capacity development objective. Most internal systems reinforce this priority and the sheer weight of work that grant management entails.

of core funding support to only hiring them on one-off contracts. The 2006 survey revealed that provision of direct support to local capacity development providers is now the least preferred approach (Lipson and Warren 2006). Only 20 per cent of the responding INGOs emphasised the importance of supporting local specialist capacity development organisations.

This may be because capacity development may be becoming the new operational arena for international NGOs. In an effort to justify their role and income to their official government back-donors they are emphasising their own ability to build local capacity in the South. This in turn may inhibit the development of local capacity development providers.

As Alan Fowler (2006) points out, the formation of professionals in this field remains episodic and incoherent. While the odd donor may provide intermittent support, in general there is a lack of investment in promoting the quality and quantity of credible and experienced capacity builders. This is reflected in lack of investment in the professional development of capacity builders; inadequate production of appropriate knowledge and resources and absence of time, places, means and systems for capacity builders to meet and exchange experience either within countries or across borders.

\subsection{How well are INGOs planning and managing the capacity development process?}

The evaluations indicate that INGO support to capacity development is still ad hoc and disconnected. There is limited oversight or integration of activities into a cohesive or strategic whole. They often fail to provide developmental funding to resource the implementation of change and rarely undertake systematic monitoring and evaluation of capacity development work.

\section{A strategic approach}

Recent studies and evaluations of international agencies in capacity development reveal that they are strategic in name, but more informal and unstructured in practice. Some two-thirds of the INGOs who responded to the 2006 survey stated that they had a 'specific programme which is solely dedicated to civil society capacity 
development' (Lipson and Warren 2006). Yet despite this, INGOs lack shared organisational definitions of capacity development. Rather, they admit to 'scattered reference in diverse documents and policy papers' (Lipson and Warren 2006). Although capacity development is often cited as a key strategic goal, only 18 per cent of 2006 survey respondents had any policy or strategy on how they would go about this (far less than in the 1998 survey).

The absence of a strategic approach leads to lack of consistency and coherence in the capacity development work undertaken across the organisation. An evaluation of an international NGO that we will call TINGO exemplifies the situation of many international agencies that claim to have prioritised capacity development (Box 1).

Shared understanding of capacity development is necessary both within each organisation, and also between the different stakeholders. There is little evidence of stakeholders taking sufficient time to reach joint definitions of terms before initiating a capacity development programme. Amidst pressure to sign contracts and reach deadlines, it is easier to leave the definition and the different interests imprecise. Consensus is achieved by not clearly identifying the goal.

\section{Focus on implementation of change}

The performance of INGOs in supporting the implementation of change is mixed. There are some positive examples of INGOs investing in follow-through. In other cases, the evidence indicates that donors are more interested in supporting needs analysis and capacity development planning events rather than resourcing the implementation of change. It is often only the planning of the job that gets funded. Capacity development events, such as strategic planning sessions, HIV policy development processes and training courses, are what get funded. The better ones end up with action plans; but then the capacity development funding stops. There is often nothing planned or provided for the change process itself. But the real work of change, which only takes place back in the organisation, has not yet begun.

The lack of focus in capacity development programmes hinders implementation of change, for example, one INGO in Africa identified between 20 and 50 capacity-building needs for each of its sub-grantees. As a result, the local organisations were overwhelmed by the number of trainings and workshops and did not have the time to implement changes in their organisations. Some were so involved with responding to the demands of the INGO for grant management requirements, the capacity-building workshops, monitoring and evaluation $(\mathrm{M} \& \mathrm{E})$ and regular networking meetings that they felt they had effectively become employees of the INGO.

\section{Developmental resourcing}

Clearly there has been significant investment in capacity development over the past 15 years. Forty five per cent of international NGOs responding to the 2006 survey estimated that they spend almost one-third of their overall programme funds on capacity development. But there are growing concerns about quality and widening awareness that good practice capacity development requires generous, but considered and careful support. In 2000, Sida recognised they 'have not devoted enough attention to issues relating to the long-term financing of contributions to capacity development' (Sida 2000: 25) An evaluation five years later found that while good practice principles of flexibility and ownership are highlighted in capacity development policy documents, grant management systems require rigid specified results before starting (Bergstrom 2005).

\section{Monitoring and learning}

A 1994 review of INGOs and capacity development concluded that 'evaluations of capacity development programmes by NGOs are extremely limited and there is little evidence from the NGOs regarding the effectiveness of their approaches... This is a significant problem given the... pressure from donors for evidence of impact' (James 1994). There has been some sporadic improvement since then. Some INGOs (such as CAFOD, Tearfund, International Federation of Red Cross and Red Crescent Societies (IFRC)) have undertaken one-off evaluations of their capacity development support. Others such as Voluntary Service Overseas (VSO), Netherlands Development Organisation SNV or Soutien aux ONG à l'Est/Support for NGOs in the East (SongES), have invested in developing comprehensive system for measuring change resulting from capacity development. But overall, progress is disappointing. 
For the most part, INGOs do not know whether capacity development programmes are really having intended impacts. Of the 57 projects identified by one UK NGO as representative of 'good capacity development practice', only three of the files ( 5 per cent) contained anything approaching reasonable information about impact. A forthcoming survey of the state of play with $\mathrm{M} \& \mathrm{E}$ of capacity building found that: 'there is very little evidence that most INGOs make any systematic attempt to carry out M\&E as part of a wider strategy. Some have concept documents or research documents that discuss M\&E of capacity building, but these have rarely been translated into organisation-wide policies or practices' (Simister 2010: forthcoming).

So if we know what to do in capacity development, why do we fail to implement it? Our mediocre practice is influenced by external contextual constraints and perhaps more significantly our internal vices.

\section{Contextual constraints}

International agencies operate within an aid system that does not always encourage good practice capacity development. The way the aid system works establishes pervasive power dynamics. In order to receive income in the form of aid grants, agencies have to play by the rules established by those who control the resources. This means that the aid system context is a powerful influence on the actual behaviour of any agencies within it, including international NGOs.

Current trends within the aid system are not conducive for international agencies to implement good capacity development practice with civil society partners. Over the last few years, donors have taken a more state-centred approach to development. This means that resources which were previously directly channelled to local civil society are now meant to go through national and local governments first. As civil society risks being relegated into a contracted-out social welfare provision role, so capacity development of civil society becomes less important.

The audit-orientation of public sector management (measureable targets, visible results, efficiency) has also permeated the aid world, negatively affecting capacity development.
Government donor agencies are increasingly driven by measures of efficiency - disbursing large sums of money in a simple, cheap way and in as short a time as possible. These act as major disincentives to implementing good quality capacity development. For example, the increasing preoccupation with proving quantifiable results within a short, project-based period makes it harder to take a long-term approach. The need for the aid system to disburse large sums of money quickly prevents an incremental approach to capacity development.

The need for CSOs to absorb significant sums of money can push CSOs way beyond their competence too quickly. Competitive bidding processes require organisations to prove they already have adequate capacity and give them no room to identify or admit weaknesses and plan how to address them.

By operating within a power-laden aid system, international NGOs open themselves up to its potentially negative influence on capacity development. As a result, we observe some international NGOs becoming more operational, moving away from 'partnerships' with local organisations to 'strategic alliances' on the basis of sub-contracts.

The external constraints in the context are not however limited to the aid system alone. It can be difficult to implement the good practice of using local capacity building providers when there are not good quality providers around. Certainly, the skill set required for providing high quality capacity development services is very demanding. Good quality providers:

- recognise and respond sensitively to the influences of culture and context;

- develop client-ownership of the process to focus on their motive for change;

- take a people-centred approach to change, work with the personal and manage tensions creatively;

- see and work with the inter-relationships between elements;

- sensitively and courageously understand and challenge power dynamics;

- have the competence to use a variety of methods, including the more experiential;

- balance structure and flexibility;

- communicate in a culturally sensitive and creative way. 


\section{Pride: seeing ourselves as better than others}

Pride may be behind the thinking we have encountered among all stakeholders: we know better what others need; we are OK, but they have a problem; we can control how others develop; we do not need help from others; I cannot admit my faults; we do not need to work with others.

\section{Greed: the acquisition of wealth or a longing to possess something}

Preoccupation with securing more funding or fees has undermined the practice of many stakeholders, pushed international agencies to take over work that could be done by local CSOs and prioritised accountability to donors over impact on the poor. It may also be about wanting to retain the power in the relationship.

\section{Lust: seeing others as a means to our gratification}

Our pride and greed give way to lust - a lust for control, power, status. We use other stakeholders as means to our ends. Partnerships exist only in name. Different stakeholders are only interested in what others can provide for them. This instrumental, impure love for others leads to a lack of courage and boldness.

\section{Gluttony: thoughtless excess, over-consumption or habitual greed}

We see this in international over-consumption of limited local human resources for capacity building. We also see this in local CSO $4 \times 4$ vehicles overwhelming communities. We see this in inflating salary levels and consultant fees...

\section{Envy: a desire to have something possessed by another}

Envy may be at the root of our failure to collaborate with other stakeholders in capacity development. Local capacity development providers see others as competition and fail to work together and learn from each other. INGOs pull local CSOs in different directions with 'their' capacity development activities.

\section{Wrath: intolerance, impatience, discrimination or extreme anger}

Wrath undermines capacity building when it leads to impatience. When artificial project deadlines prove unrealistic, this can lead to frustration and even anger.

\section{Sloth: reluctance to work or make an effort and failure to use/develop talents}

Different stakeholders sometimes do not bother to apply their knowledge and are too lazy to prioritise. We do not actively seek to develop and implement our knowledge about capacity development. We often fail to have the determination to see it through.

There are not enough people who meet such demanding criteria to implement good practice capacity development. Although the early 1990s witnessed a growth of capacity building providers, since the late 1990s this growth suddenly stopped. The number of capacity development providers is contracting, particularly in Eastern Europe and Africa. Some have closed down, such as Olive in South Africa, while others have contracted and lost staff. All are facing considerable challenges. They meet a vital need, but are in a fragile state, starved of human, leadership and financial resources.

\section{Vices and deadly sins}

But everything cannot be blamed on this difficult context. Good practice can still take place in a harsh environment. There are deeper influences at play. How agencies choose to respond to the challenging context depends on organisational character - the extent to which agencies are driven by their vices or whether they can live out virtues.

International agencies are intermediaries, raising money from donors and spending it on grants and activities. They are inherently pulled in two 
different directions. Good practice capacity development may say one thing, but good practice fund-raising may say the opposite. Which voice shouts loudest? Who gets listened to? Today, capacity development practice tends to suffer when pitted against fundraising opportunities. It is a courageous INGO manager who turns down future funding on the grounds that it does not fit easily with good practice capacity development.

In the scramble to increase or maintain turnover in an increasingly competitive market, international NGOs and donors are adjusting policies and procedures to fit with the new aid architecture. To secure large contracts and grants, international agencies are tempted to simplify capacity development into over-ambitious plans. There is rarely time for consultation with local CSOs, let alone to allow them to 'take responsibility' for the capacity development. Given the aid trends, donors are often under pressure to deliver quick and unrealistic results.

Once funding is secured, the accountability obligations can foster a consolidation of international control. Compliance becomes the name of the game. INGOs are pushed into 'micromanaging' partners to deliver according to pre-set targets. All this flies in the face of good practice capacity development (and other forms of human and social development). Information systems are set up to serve the needs of those controlling the money. Donors develop accountability-oriented systems, not capacity development-oriented systems. When there is a conflict between the two, accountability is prioritised above ensuring capacity development impact.

The preoccupation with funding is symptomatic of a deeper question of attitude. This is illustrated by the Northern-oriented capacity development needs prioritised for Southern CSOs by Northern donors. Capacity development for local CSOs is what will help the donor disburse funds, provide accountability and manage risk.

The international NGO refrain of 'trying to work ourselves out of a job' seems to have gone out of fashion. Growth, survival and self-interest have come to the fore. In some contexts, we see INGOs becoming more operational, displacing local CSOs and taking the place of local capacity development providers. They are also undoubtedly distorting the market for local CSO staff. In Malawi for example, there are probably three times as many INGO staff than local CSO staff - and we wonder why there are capacity issues in local CSOs. INGOs are consuming the best of limited local capacity.

Fears also undermine international agencies' commitment to operationalising good practice. It is easier to talk about shifts in power and relationships in principle, than to apply them to actual relationships with local CSOs. In other cases, it may be fear of failure - apprehension of what may be found - that holds INGOs back from more systematic monitoring and evaluation of capacity development.

Some of these constraints in attitude reflect basic aspects of human nature. We do not practice what we know in capacity development because we succumb to vices or what Catholics would call 'deadly sins' (Box 2).

These vices are obviously not restricted to international NGOs alone. Capacity development providers may have skills and resources, but lack the character:

- to have the courage and determination to see through difficult, time-consuming processes;

- to respond to the donor as the real client, rather than the CSO;

- to be committed to relentless improvement or to gender equality;

- to not compromise on principles and values in order to get contracts (i.e. by providing a kickback to whoever is offering the contract);

- to not concentrate on the weaknesses of clients in order to portray themselves as 'experts'.

Also local CSOs are not always innocent victims in the failure to practice good quality capacity development. They also succumb to these vices. For some, their pre-occupation with action and short-term financial survival prevents them from looking honestly and internally at their own organisations. They appear caught in a relentless spiral of activity, forever too busy to stop and think about their own future capacity needs and to plan accordingly.

The frequent preoccupation with short-term survival has blinded many CSOs to their own 


\section{Humility: modest behaviour, selflessness, giving of respect - opposes pride}

We know capacity development is an endogenous process, not something you can do to another NGO. Therefore, international NGOs need to recognise they cannot do it alone; it is a collective effort. To support capacity development well also requires the humility to be open to learning and change your own organisation if it is inhibiting the process.

\section{Compassion: kindness, contentment, satisfaction - opposes envy}

Compassion is about putting partner needs first; wanting the best for their organisation, not your needs (e.g. for improved reporting). True compassion includes a sense of justice for the poor. It can be salutary for any INGO to (re)assess their actions against their mission. Sometimes they inadvertently find they are taking a competitive stance to other INGOs for their own benefit, rather than ultimately for the benefit of the community.

\section{Patience: forbearance, peace, ability to forgive - opposes wrath}

Capacity development can be difficult and frustrating. It involves changing power and relationships among stakeholders. People do not change as quickly as we would like. In consequence, for INGOs to be effective, they need to be patient. Capacity development does not always work. It can often be a process of trial and error. INGOs need the patience of character to learn from failure.

\section{Determination: diligence, passion, courage - opposes sloth}

Good INGOs are relentless in implementing good practice. They have disciplined thought and actions, realistic goals, clear strategy, good practice methods, rigorous monitoring and evaluation systems, innovative organisational learning, flexibility and accessible documenting. They push themselves to do what is right, not expedient. They demonstrate their commitment to capacity development by investing quality resources (finances, staff and management time).

\section{Generosity: sacrifice - opposes greed}

To implement good practice capacity building requires a generous attitude. Generous in sharing learning and in looking to what others can receive from their inputs (not putting their own interests first). Being generous means focusing on what is good and life-giving in a situation, not just the obvious problems.

\section{Self-control: mindfulness of other, temperance - opposes gluttony}

Implementing good practice capacity building requires international agencies to be mindful of others and their surrounding context. They exercise self-control, not merely poaching the best local NGO staff because they can pay them more. They are careful stewards of their resources, including staff time.

\section{Honesty: openness, purity - opposes lust}

To implement good capacity development programmes requires honesty. Any agency brings an agenda into a programme. It is important to acknowledge this self-interest in order to be able to manage it and control it. Good international agencies are consistent - being as open with their partners about internal information as they demand from them.

capacity issues. When asked what is needed for them to improve, the knee-jerk response is 'more money'. In some cases, the main concern is how to pay salaries at the end of the month, rather than what difference they are making in the lives of poor people. The focus has shifted from impact to survival. So the capacity development is merely viewed as a means to an end - of getting grant funding. If offered, many CSOs would probably prefer cash rather than capacity development. 
This is often a problem of poor vision and leadership within CSOs or perhaps even greed.

International agencies tend to blame local partners for problems and many local organisations apportion blame to donors. Rather than recognise their own weaknesses in order to address them, many CSOs feel more comfortable blaming others. They have limited ownership of capacity development, not because the opportunity for taking ownership is not there, but because they have become comfortable in the 'victim' role. This may be related to a lack of selfworth and dignity or even pride in refusing outside help.

So if vices are at the heart of the problem, perhaps virtues, their antithesis, should be at the core of the solution.

\section{Virtues in capacity development}

Virtues are by no means a new concept. Aristotle described virtue as 'the state which makes a man good and which makes him do his work well (quoted by Caza 2002: 10). Virtues are not the same as values because they bring in notions of moral absolutes; of right and wrong. While values looks at peoples' underlying assumptions and expectations (which can be good or bad), virtues asks about what is good and what brings life. So, while values are common parlance in management, virtues have been largely ignored in a relativist and post-modern world.

But this neglect of virtues in management appears to be changing. An increasing number of organisational writers and theorists are investigating the apparently positive relationship between organisational virtues and performance (Caza 2002; Cameron, Dutton and Quinn 2003; Moore and Beadle 2006; Manz, Cameron, Manz and Manz 2008).

Many of these take MacIntyre's (1985) classic work After Virtue as a starting point. Moore and Beadle (2006) use Traidcraft as a case study to explore the relationship between being able to practice excellence in a particular field and the institutional virtues needed to protect and extend that. They focus on institutional character, which depends on the relationship between the individual staff, the institution itself and the external environment. They argue that institutional virtues are needed to resist 'the corrupting influences and constraints in the external environment' (Moore and Beadle 2006).

Agencies wishing to protect and extend excellence in capacity development may need to live out these institutional virtues, instead of succumbing to the opposing vices. For international NGOs, supporting capacity development such virtues might be as shown in Box 3.

\section{Conclusions}

Although we know what to do in capacity development, we do not do it. External contextual factors undoubtedly constrain our ability to put into practice what we know. But it is deeper than that. As Monica Sharma of UNDP states: 'the underlying causes of underdevelopment and the patterns that perpetuate it - the deep-rooted, almost hidden ones - lie in the domain of personal and social attitudes, perceptions, beliefs, practices and norms. These then, should be the areas of principle concern' (Sharma 2006: 21).

At the heart, it is organisational character, our vices and our virtues, that determines behaviour. Although international agencies do have to adapt to the environment, character can be a buffer to some of the negative pressures within the aid context. Certainly the power dynamics inherent in the aid system can encourage organisational vices, but it does not make them impossible to avoid, or acceptable. Indeed, rather than simply accepting these negative pressures in the current aid system, international agencies should refuse projects which they know to be inconsistent with good practice. They can even go further and advocate against contextual trends. It may be that the system needs to be restructured to better support good practice.

Ultimately, to implement good practice capacity development requires organisations to acknowledge and restrain their vices. But they need to go further to cultivate the antidote namely virtues. Living out virtues of humility, compassion, patience, determination, generosity, self-control and honesty in capacity development would transform our practice. If we had the courage to combine such virtues with the professional knowledge we already have of what works, then our capacity development practice would not only live up to our theory; more importantly it would change lives. 


\section{Note}

1 Obviously these may be beneficial to the Southern CSO, but are rarely prioritised by them unless they are thinking about what the donor wants to hear.

\section{References}

Baser, H. and Morgan, P. (2008) Capacity, Change and Performance Study Report, ECDPM

Discussion Paper 59B, Maastricht: European Gentre for Development Policy and Management

Beauclerk, J. (2007) Strengthening the Capacity of Strategic NGOs in Macedonia, Internal INTRAC report, Oxford: International NGO Training Research Centre

Beauclerk, J. (2006) Evaluation of Ecumenical Consortium for Central Asia, Internal INTRAC Report, Oxford: International NGO Training Research Centre

Bergstrom, L. (2005) Development of Institutions is Created from the Inside, Sida Studies in Evaluation 05/04, Stockholm: Sida

Cameron, K.; Dutton, J. and Quinn, R. (eds) (2003) Positive Organizational Scholarship: Foundations of a New Discipline, San Francisco CA: Berrett-Koehler Publishers

Caza, A. (2002) 'Organisational and Leadership Virtues and the Role of Forgiveness', Journal of Leadership and Organisational Studies, www.allbusiness.com/human-resources/ employee-development-leadership/3453161.html (accessed 12 January 2010)

DAC Network on Governance (2006) The Challenge of Capacity Development: Working Towards Good Practice, www.worldbank.org/ INTCDRC/ Resources/oecd_challenge_of_capacity_ development.pdf (accessed October 2006)

Eyben, R. (ed.) (2006) Relationships for Aid, London: Earthscan

Fowler, A. (2006) Systemic Change for Promoting Local Capacity Development, Working Paper for Stichting Nederlandse Vrijwilligers (SNV), Johannesburg: Netherlands Development Organisation

James, R. (1994) Strengthening the Capacity of Southern NGO Partners: A Survey of Current Northern NGO Approaches, OPS 5, Oxford: International NGO Training Research Centre (INTRAC)

James, R. and Hailey, J. (2007) Capacity Building for NGOs: Making it Work, INTRAC Praxis Series 2, Oxford: International NGO Training Research Centre (INTRAC)
James, R. and Wrigley, R. (2007) Investigating the Mystery of Capacity Building: Learning from the Praxis Programme, Praxis Paper 18, Oxford: International NGO Training Research Centre (INTRAG)

Lipson, B. and Warren, H. (2006) 'International Non-Governmental Organisations' Approaches to Civil Society Capacity Building: Overview Survey', INTRAC Paper for Capacity Building Conference, Oxford, http://intrac.org/pages/CBProgramme.html (accessed 16 December 2009)

MacIntyre, A. (1985) After Virtue: A Study in Moral Theory, 2nd edn, London: Duckworth

Manz, C.; Cameron, K.; Manz, K. and Manz, R. (2008) The Virtuous Organization: Insights from Some of the World's Leading Management Thinkers, Singapore: World Scientific Publishing

Moore, G. and Beadle R. (2006) 'In Search of Organizational Virtue in Business: Agents, Practices, Institutions and Environments', Organization Studies 27: 369-90

Morgan, P. (2006) The Concept of Capacity, Maastricht: European Centre for Development Policy and Management (ECDPM)

Partnership Africa Canada (1986) Partnership Matching Rhetoric to Reality, Ottawa: PAC

Sharma, M. (2006) 'Conscious Leadership at the Crossroads of Change', Shift: At the Crossroads of Consciousness 12: 16

Simister, N. (2010 forthcoming) Monitoring and Evaluating Capacity Building: Is it Really that Difficult?, Oxford: International NGO Training Research Gentre (INTRAC)

Sorgenfrei, M. (2004) Capacity Building from a French Perspective, Praxis Paper 1 INTRAC, Oxford, http://intrac.org/pages/ PraxisPaper 1.html (accessed 13 January 2010)

UNDP (2006) Capacity Development Practice Note, www.capacity.undp.org/index.cfm? module $=$ Library\&page $=$ Document $\&$ DocumentID $=$ 5599 (accessed 27 November 2006)

World Bank (2006) Capacity Building in Africa: An OED Evaluation of World Bank Support, www.worldbank.org/oed/africa_capacity_ building/ (accessed 12 August 2007)

Wrigley, R. (2006) Learning from Capacity Building Practice - Adapting the 'Most Significant Change' 
(MSC) Approach to Evaluate Capacity Building Provision by CABUNGO in Malawi , Praxis Paper 12, Oxford: International NGO
Training Research Centre (INTRAC), http://intrac.org/pages/PraxisPaper 12.html (accessed 13 January 2010) 